\title{
A HISTÓRIA ECONÔMICA DO BRASIL (1500/1820), DE ROBERTO SIMONSEN
}

\section{THE ECONOMIC HISTORY OF BRAZIL (1500/1820), BY ROBERTO SIMONSEN}

\author{
Igor Zanoni Constant Carneiro Leão*
}

\section{RESUMO}

A História Econômica do Brasil (1500/1820), de Roberto Simonsen, publicada em 1936, representa por seu escopo, método e valores, texto pioneiro ainda fundamental para o estudo da história e da historiografia brasileiras. O artigo destaca os elementos estruturadores do livro deste grande industrialista e homem público, bem como sua ideologia subjacente.

Palavras-chave: Pensamento econômico brasileiro. Ideologia desenvolvimentista. Roberto Simonsen.

\begin{abstract}
Due to its purpose, method and worth, Economic History of Brazil (1500/1820), published in 1936, by the great industrialism supporter and public man Roberto Simonsen, represents an essential and pioneer work concerning with Brazilian history and historiography studies. This article discuss about the structural elements of Simonsen's book, as well as his implicit ideology

Keywords: Brazilian economic thought. Ideology of development. Roberto Simonsen.
\end{abstract}


A historiografia consagrou a História Econômica do Brasil (1500/1820), de Roberto C. Simonsen, ao lado de Formação do Brasil Contemporâneo, de Caio Prado Júnior e Formação Econômica do Brasil, de Celso Furtado, como os três textos clássicos sobre o período colonial brasileiro. O primeiro foi publicado em 1936, o segundo em 1942 e, finalmente, o terceiro em 1959. Essa sucessão de datas já indica uma dependência ou uma referenciação dos textos posteriores ao primeiro, que pode ser considerado pioneiro, por seu caráter abrangente e analítico. Neste texto, desejamos indicar pontos na obra de Simonsen que podem subsidiar o estudo de sua visão do Brasil, e mesmo sua visão de mundo, às vésperas do Estado Novo.

A História cria um roteiro de temas utilizados nos dois livros posteriores que citamos, como os primórdios da colonização, as políticas coloniais, o ciclo do açúcar, a mão de obra servil, a expansão da pecuária e sua importância na ocupação do território, o ciclo da mineração e a ocupação do Amazonas. Estes temas recebem um tratamento bastante erudito, recorrendo a fontes veneráveis que conheceram a colônia e expuseram diversos aspectos de sua economia e sociedade. Além disso, Simonsen se apoia também em alguns autores modernos como Paulo Prado e Gilberto Freyre, entre outros.

Ao mesmo tempo, Simonsen faz uma ampla elaboração estatística sobre cada tema estudado, indicando um enorme lavor na busca de documentos os mais diversos, no Brasil e na Europa. Muitos desses dados, como se sabe, fornecerão os elementos para análise de Furtado, sob outra ótica e interesse. Menos dito é que o livro de Caio Prado Júnior, ainda que use muitas das fontes e autores de Simonsen, chega a resultados diversos, dada sua própria ótica valorativa e política.

Situemos, a partir daí, nosso autor e nosso livro em 1936. Simonsen, já na década anterior, havia se tornado um preeminente industrial em São Paulo, fundando, com Francisco Matarazzo e Jorge Street, em 1928, o Centro de Indústrias do Estado de São Paulo - CIESP, e foi um dos criadores, em 1931, da Federação de Indústrias do Estado de São Paulo - FIESP. Também se torna um estudioso reconhecido de problemas econômicos e sociais brasileiros, fundando, em 1933, a Escola Livre de Sociologia e Política de São Paulo, juntamente com intelectu- ais envolvidos no panorama político imediatamente posterior à Revolução Constitucionalista, de 1932.

Essa Escola buscava a formação de "elites" a partir do estudo de política, sociologia e economia, para criar uma consciência nacional que orientasse a administração pública. Desse ponto de vista, a $E s$ cola buscava dissipar a "incompreensão reinante no Brasil, da qual São Paulo era a principal vítima”. O livro de Simonsen consiste em uma série de conferências sobre a colônia, ali proferidas no curso sobre a economia brasileira que ministrava.

Sua justificativa para estudar a história econômica apoia-se em Karl Marx, o qual, segundo Simonsen, "via em todos os acontecimentos políticos, gerando-os e explicando-os, o substrato econômico" (SIMONSEN, 1978, p.24). Apoia-se, também, em Sombart, que teria atingido, com sua obra sobre o capitalismo moderno, o ponto culminante e contemporâneo do estudo sobre as origens do capitalismo. Por outro lado, este estudo é necessário na formação de um organismo social forte, criador de condições favoráveis de vida, uma vez que: "Do aperfeiçoamento dessas condições, resultará o fortalecimento do Estado, numa linha ascendente de progresso, e a segurança de uma posição respeitável econômica e politicamente no concerto das demais nações" (Ibid., p.23). O estudo da economia colonial é fundamental, pois na era colonial formou-se a trama social que assegurou a unidade do país, a partir dos fatores econômicos na sua formação. Passemos agora aos pontos do livro que desejamos destacar.

Em primeiro lugar, a colônia brasileira nasce no contexto da revolução comercial do século $\mathrm{XV}$, relacionada com o pioneirismo português no movimento navegador. Nesta fase, os nascentes estados nacionais buscavam intensificar as correntes de comércio internas, articuladas com a busca de saltos comerciais favoráveis e segurança militar frente a outros estados. A procura por metais preciosos é um elemento central nesse período para o enriquecimento e segurança do reino, sustentando sua capacidade produtiva e os preços de seus produtos. A colônia nasce, pois, no quadro da formação do sistema econômico capitalista, que amadurece com a revolução industrial inglesa do final do século XVIII.

A colônia brasileira tem sua formação ancorada em dois pontos centrais: a rivalidade entre os estados absolutistas e o conjunto do império 
colonial português. Assim, ela só é objeto de políticas coloniais, como o exclusivo metropolitano, após Portugal firmar seu domínio na região em relação a outras potências que a disputavam. Por outro lado, essa formação dependeu da perda do rico comércio com as Índias Orientais para a Holanda e Inglaterra, obrigando Portugal a uma colonização sistemática de um território de extensão mal conhecida, vazio de uma civilização com a qual pudesse comerciar como fora o caso na Índia, e carente de braços para a tarefa de construir uma economia colonial de exploração assentada em estruturas produtivas complexas e inéditas.

Nasce, aí, um conjunto de políticas que implicará um enorme esforço por Portugal de articulação de políticas coloniais, como a repartição das terras em donatarias, o financiamento de sua exploração, a administração portuguesa na colônia com a instituição do Governo-geral visando garantir segurança aos donatários, bem como ordem e cooperação entre eles. Esse esforço também implica a construção de armadas, forças militares, entre outros, que propiciarão a construção da economia açucareira nordestina, fixando, após a efêmera exploração do pau-brasil, uma nova sociedade nos trópicos. O centro dessa sociedade é o engenho, com toda sua complexa estrutura de ofícios, poder e trabalho escravo. Fica claro o elevado custo dessa exploração, minuciosamente descrita a partir de textos e dados estatísticos disponíveis em Antonil, João Lúcio de Azevedo, entre outros autores.

O sucesso desse empreendimento leva, após a união dos reinos de Portugal e Espanha, ao período holandês em Pernambuco, só concluído com a revolta dos antigos ocupantes e elevada indenização de Portugal à Holanda. Pode-se perceber, neste episódio, que a exploração da colônia envolvia o interesse do Reino bem como o dos colonizadores, nem sempre convergente.

A base da sociedade açucareira era o trabalho escravo, tornado abundante pelas guerras que Portugal manteve em Angola e outras colônias africanas, exploradas com essa finalidade. O Brasil era a colônia em torno da qual girava o Império Português, e o Reino dependia crescentemente dos frutos que aqui pudesse obter. Entende-se, portanto, que a escravidão negra tenha tomado impulso no século XVII no período áureo da indústria açucareira. $\mathrm{O}$ tráfico era em si mesmo um negócio extremamente rentável ao governo português, o qual chegou mesmo a monopolizá-lo durante certo tempo. A exploração colonial assenta-se, portanto, em três elementos: o exclusivo de comércio, o trabalho escravo e a grande propriedade fundiária.

Simonsen justifica a escravidão negra apoiando-se em Gilberto Freyre:

Ainda assiste razão a Gilberto Freyre, quando diz: "Deixemo-nos de lirismo com relação ao índio. De apô-lo ao português como igual contra igual. Sua substituição pelo negro - mais uma vez acentuemos - não se deu pelos motivos de ordem moral que os indianófilos tanto se deliciam em alegar; sua altivez diante do colonizador luso em contraste com a passividade do negro. O índio, precisamente pela sua inferioridade de condições de cultura - a nômade, apenas tocada pelas primeiras e vagas tendências para a estabilização agrícola - é que falhou no trabalho sedentário. O africano executou-o com decidida vantagem sobre o índio, principalmente por vir de condições de cultura superiores. Cultura já francamente agrícola. Não foi questão de altivez, nem de passividade moral" (ibid., p.132).

Simonsen assume, pois, a visão de um índio com mentalidade atrasada, sem resistência física, sem a compreensão da necessidade do trabalho, tornando catastrófica a sua escravidão. Nesse sentido, tornava-se o índio um necessitado, que precisava ser amparado, como o foi pelos jesuítas, nem sempre de acordo com a legislação portuguesa ou com interesses dos colonos. É possível ver aí uma valoração de uma ética do trabalho no esforço colonizador, contra a "ética da aventura do desleixo" que, segundo Sérgio Buarque de Holanda em Raizes do Brasil, o teria animado sob a lógica do grande capital mercantil, que impede na colônia um esforço racional e melhor organizado.

Ao mesmo tempo, nosso autor justifica a escravidão com a lei da produção econômica:

A lei do menor esforço, observa George Scelle, sempre atuou na produção econômica. No domínio social, ela se traduziu no aproveitamento de uma superioridade física, moral ou legal para apropriação, com um mínimo de esforço, de uma máxima utilização do trabalho alheio. 
Resultou de sua influência que a parte mais penosa do trabalho foi transferida para aqueles que a natureza ou a organização social colocou em estado de inferioridade. E a remuneração seria tanto mais fraca quanto mais acentuada essa inferioridade; cessando mesmo no estado de servidão, em que o homem, transformado em coisa ou máquina, só recebia a indispensável nutrição para ser mantido em estado eficiente.

Foi esta, infelizmente, a triste história da evolução do trabalho. (...)

Os altos sentimentos humanitários, revelando uma cultura e uma civilização mais avançada só se tornaram vitoriosos nos vários Estados, quando se atenuou, por um enriquecimento mais generalizado, a luta pela subsistência. O mal fundamental dos regimes políticos e sociais do passado consistiu na criação de castas, na limitação de suas possibilidades, nas tentativas de circunscrição, de enriquecimento dos povos a determinadas classes privilegiadas, quando o objetivo da civilização deve ser a difusão do bem estar e da cultura pelo maio número, o maior progresso distribuído pela maior massa (ibid., p.140-144).

Assim, esse ideal utilitarista só pode se afirmar quando cessa a luta pela subsistência, e os regimes políticos e sociais do passado, nos quais essa luta ainda não estava definida, não puderam atingi-lo, o que, de certa forma, justifica neles um regime como a escravidão sobre os culturalmente inferiores.

A relação entre missionários jesuítas, colonos e indígenas segue uma lógica semelhante. Isto pode ser visto na história das Missões, quando a Coroa decide ocupar a costa norte do Brasil. Esta ocupação se faz, a princípio, com colonos na costa do Maranhão, de forma instável e precária, baseada no tráfico de escravos índios e uma pequena exportação de algodão e outros produtos baseada também no trabalho servil do índio. Na primeira metade do século XVIII, o comércio das drogas do sertão no vale amazônico passa a constituir a riqueza das missões religiosas que procuram proteger os indígenas que pereciam nesse regime de trabalho. Simonsen destaca a motivação dos jesuítas neste momento:

Os jesuítas e outras ordens religiosas, que ansiavam por trazer à Igreja as grandes populações de infiéis, numa época em que as lutas religiosas tinham por demais exacerbados os espíritos no continente europeu, adotavam programa diametralmente oposto ao dos colonos. Seu desinteresse inicial pelos bens terrenos, seu espírito de sacrifício e, para muitos, a ambição do próprio martírio, conduziu os missionários à defesa intransigente da liberdade dos silvícolas, desejando conservar essa massa virgem para o trabalho integral da catequese. Daí a luta que se propagou por toda a América e que apresentou diferentes aspectos, em função dos valores geo-econômicos das regiões ocupadas e do tempo em que ocorreu tal ocupação (ibid., p.313).

A Igreja, o governo português e o de Castela buscaram proteger a população indígena regulando a administração das aldeias e protegendo as atividades dos jesuítas. Assim, o padre Antônio Vieira recebe autorização, em 1652, para levantar igrejas, estabelecer missões, descer índios ou conservá-los em suas aldeias, podendo pedir auxílio dos governadores e outras autoridades. A pobreza dos colonos do estado do Maranhão, criado em 1620, fazia com que estes colocassem contra tais atividades. Há, a partir daí, uma luta envolvendo jesuítas e colonos envolvendo a utilização do trabalho indígena. Os jesuítas propunham a proibição dos resgates dos índios e o desenvolvimento das missões em troca da introdução de escravos de Angola pela Coroa.

Funda-se, então, a Companhia do Comércio do Maranhão, com contrato de vinte anos e a obrigação de introduzir, nesse prazo, dez mil negros na colônia, além de fornecer todos os gêneros de consumo por preços pré-fixados. Todavia, esta companhia não cumpre com seus objetivos, e há uma reação que chega à revolta encabeçada por Beckmann. Os jesuítas são deportados, então, mas conseguem, mais tarde, descer o vale do Amazonas, criando missões que salvaguardam do extermínio grande parte da população nativa, integrando-a na sociedade colonial e criando uma civilização na bacia amazônica.

Todavia, a Companhia de Jesus acumula contra si um ódio crescente, dada a miséria dos habitantes da costa e as lendas sobre a prosperidade das missões. Sob o governo do Marquês de Pombal, a partir de 1750, a busca do fortalecimento econômico de Portugal e a cobiça em torno da riqueza presumida dos jesuítas, fazem com que estes sejam expulsos da colônia e tornam legais as investidas sobre os índios, para serviço público ou para o uso de particu- 
lares. A riqueza das missões mostrou-se ilusória, e se acentua a decadência dos nativos, ainda que o governo de Maria I procure regular o uso do trabalho e a vida dos índios nos povoados.

A conclusão de Simonsen sobre estes conflitos e a consequente quase extinção dos indígenas é a seguinte:

A série de leis promulgadas para o Brasil a fim de proteger a liberdade dos índios e os sucessos verificados com a sua aplicação mostraram, como aliás em outras partes do mundo, a improficuidade de tais leis em face aos perigos que, do contato entre uma raça civilizada e outra atrasada, decorrem para esta última. Por mais paradoxal que isso pareça, a história comprova que a mais civilizada e forte destrói a mais fraca (ibid., p.341).

O genocídio indígena é visto, pois, como um inevitável choque civilizatório, ao mesmo tempo em que o nosso autor valoriza fortemente a atuação de Pombal face ao Brasil:

Teve uma preocupação predominante durante o seu longo governo: defender, a todo transe, a colônia da cobiça estrangeira e assegurar a posse e o alargamento de suas fronteiras.

É verdade que várias de suas leis foram contraditórias e que nem sempre acertou em relação às medidas mais adequadas ao progresso brasileiro, mas o período de paz que proporcionou a Portugal refletiu-se, com vantagem, nas relações de comércio com o Brasil; e o reerguimento econômico que preparou para o reino veio permitir enorme florescimento da expansão comercial do Brasil no final do século XVIII (ibid., p.377).

Este florescimento deveu-se às exportações de algodão no Maranhão devido à guerra de independência americana e à industrialização inglesa. $\mathrm{O}$ estado crítico em que vivia Portugal após 1703, ano em que foi celebrado o Tratado de Methun, fez com que o reino vivesse quase exclusivamente da exploração de sua colônia brasileira. Entretanto, os jesuítas cumpriram um papel de integrar a esta colônia uma vasta região no noroeste, sendo sucedidos por uma agressiva política, favorecendo sertanistas e desbravadores, bem como pela recém-criada Companhia Geral do Comércio do Grão-Pará e Maranhão, a qual introduz braços africanos, sementes de arroz da Carolina, máquinas de descasque de arroz e melhores processos de cultura do algodão. Todavia, não ocorre uma integração efetiva na economia nacional do vale amazônico, problema ainda pendente.

No Brasil açucareiro, os recursos abundantes permitiram a substituição do braço índio pelo braço negro, mas na capitania paulista até o ciclo da mineração, prevaleceu a escravidão do nativo. Em todo sul da colônia, as missões são destruídas devido à pobreza das populações dessa região e sua demanda por indígenas que pudessem escravizar.

$\mathrm{Na}$ verdade, outro tema central no livro de Simonsen é a valorização dos colonizadores paulistas. Estes, num primeiro momento, devido a preocupações econômicas, adentram os sertões em pesquisas exploradoras e na caça ao índio, ao mesmo tempo garantindo a posse da terra para a colônia portuguesa e despovoando-a das populações originárias. Os paulistas são responsáveis, mais tarde, pelo repovoamento do interior da colônia via penetrações através das bandeiras no Paraná, Santa Catarina e Rio Grande do Sul, ao mesmo tempo em que atravessa o rio São Francisco até atingir o sertão nordestino e, mais tarde, após o ciclo do ouro, ocupam as regiões de Mato Grosso e Goiás, adentrando o vale amazônico. Fica clara sua importância na delimitação do contorno geográfico da colônia, que se vê bastante alargado, ao mesmo tempo em que fixa em suas diversas regiões populações de origem paulista.

Há, portanto, um período de despovoamento seguido por um ciclo repovoador. Este atinge seu auge com a descoberta das minas no centro do país:

O apogeu do ciclo repovoador é atingido no grande fluxo minerador. Aí a pequena população piratiningana lançou-se à exploração das imensas riquezas, que havia descoberto, mas estas eram de tamanha valia que provocaram o povoamento do Brasil e despertaram a atenção mundial para o maior centro de produção aurífera até então existente (ibid., p.239).

As ondas invasoras nas Minas Gerais e o desmembramento destas da capitania paulista levaram os paulistas, após a guerra dos Emboabas, para a busca do ouro em Goiás e Mato Grosso, bem como afluentes do Amazonas, repovoando definitivamente os sertões e formando uma infraestrutura econômica unitária no Brasil colônia. Estes movimentos são assim valorizados por Roberto Simonsen: 
Assim como Portugal se viu esgotado em seu esforço para a formação de um império mundial, Piratininga esvaiu-se nos tempos coloniais, na política expansionista que foi obrigada a abraçar por imperativos econômicos; mas o núcleo que aqui ficou encontrou, finalmente, a base econômica que tanto procurara e de que carecia para sua evolução social, em harmonia com o seu próprio valor.

Se conseguir, porém, com as economias de um trabalho eficiente, acumular novas energias e amplos recursos, estar-lhe-á talvez reservado o papel de forte cooperadora no reerguimento econômico das vastas regiões brasileiras, que os seus maiores, outrora, descobriram, conquistaram e ajudaram a povoar (ibid., p.341).

É possível perceber as dificuldades que os paulistas encontram para se fixar na colônia devido à pobreza que sofrem inicialmente em Piratininga e a animosidade da Coroa que é conivente com a sua expulsão das Minas Gerais, resultando, entretanto, em um elemento fundamental na construção da sociedade nacional. Esta é uma das conclusões centrais do texto, buscando dar relevo ao papel de São Paulo em um momento de reorganização do Estado nacional e redefinição, em uma conciliação pelo alto, das relações entre elites regionais, classes médias e a crescente classe trabalhadora.

Outro elemento fundamental destacado pelo autor na ocupação do território e sua expansão foi a atividade pecuária, a princípio como desdobramento da economia açucareira nordestina, depois como expansão criadora em Minas, Goiás e Mato Grosso, até a predominância sulina a partir do século XVIII. $O$ gado era um elemento fundamental na subsistência das populações sem uma articulação com o exterior tal como ocorria com a grande lavoura de cana e o engenho. A descoberta das Minas Gerais faz com que a pecuária encontre aí sua grande oportunidade comercial, tornando-se a região um eixo central de toda a economia da colônia.

Este eixo, entretanto, foi possibilitado pelo enorme trabalho de construção de estradas e currais desde as fazendas até o seu destino. Pensamos, por exemplo, no percurso que o gado percorria desde o Sul, pela estrada de Viamão, subindo pelos campos de Curitiba até Sorocaba e daí até as Minas. Estrada construída com extrema dificuldade dado o território inexplorado e as técnicas da época. Porém, a pecuária, tanto a bovina como a muar, cria em todo Brasil culturas regionais e populações características, permitindo as correntes comerciais pelo interior do Brasil. Simonsen estende-se cuidadosamente por todas essas correntes e populações, que permitiram o surgimento de feiras e cidades, desempenhando, a seu ver, papel saliente na formação econômica brasileira a partir do matuto e do gaúcho no Sul e do sertanejo e do vaqueiro no Norte.

A pecuária vem em socorro da pobreza de que sofre a maior parte dos colonos. Essa pobreza vem dos dízimos e impostos diversos, do peso da enorme máquina burocrática, da deficiente operação das companhias de comércio, mas, sobretudo, do tráfico e da escravidão, mas esta percepção não condiz com a de nosso autor. Mesmo no rico território açucareiro ela é mais clara, por exemplo, em Joaquim Nabuco:

O Norte todo do Brasil há de recordar, por muito tempo, que o resultado final daquele sistema é a pobreza e a miséria do país. Nem é de admirar que a cultura do solo por uma classe sem interesse algum no trabalho que lhe é extorquido dê esses resultados. Como se sabe, o regime da terra sob a escravidão consiste na divisão de todo o solo explorado em certo número de grandes propriedades. Esses feudos são logo isolados de qualquer comunicação com o mundo exterior; mesmo os agentes do pequeno comércio, que neles penetram, são suspeitos ao senhor, e os escravos que nascem e morrem dentro do horizonte do engenho ou da fazenda são praticamente galés. A divisão de uma vasta província em verdadeiras colônias penais, refratárias ao progresso, pequenos achantis em que impera uma só vontade, entregue às vezes a administradores saídos da própria classe dos escravos, e sempre a feitores, que em geral são escravos sem entranhas, não podem trazer benefício algum permanente à região parcelada, nem à população livre que nela mora, por favor dos donos da terra, em estado de contínua dependência (NABUCO, 1982, p. 80).

Esta conformação do engenho de açúcar e sua estrutura social foi também percebida por Celso Furtado, dentro de outro marco analítico, como impeditivas da formação de um processo endógeno de acumulação e crescimento da renda no interior da região a partir da exportação do açúcar. De fato, os fluxos de comércio ocorrem, sobretudo, entre o engenho e a metrópole, não originando circuitos 
internos significativos a partir deles (FURTADO, 1974). É possível perceber na análise de Furtado análise anterior de Joaquim Nabuco:

Por isso também, os progressos do interior são nulos em trezentos anos de vida nacional. As cidades, a que a presença dos governos provinciais não dá uma animação artificial, são, por assim dizer, mortas. Quase todas são decadentes. A capital centraliza todos os fornecimentos para o interior; é com o correspondente do Recife, da Bahia ou do Rio, que o senhor de engenho e o fazendeiro se entendem, e, assim, o comércio dos outros municípios da província é nenhum. $\mathrm{O}$ que se dá na Bahia e em Pernambuco dá-se em toda parte. A vida provincial está concentrada nas capitais, e a existência que essas levam, o pouco progresso que fazem, o lento crescimento que têm mostram que essa centralização, longe de derramar vida pela província, fá-la definhar. Essa falta de centros locais é tão grande que o mapa de cada província poderia ser feito sem se esconder nenhuma cidade florescente, notando-se apenas as capitais. Muitas destas mesmo constam de insignificantes coleções de casas cujo material todo, e tudo o que nelas se contém, não bastaria para formar uma cidade norte-americana de décima ordem. A vida nas outras é precária, falta tudo o que é bem-estar; não há água encanada nem iluminação a gás, a municipalidade não tem a renda de um particular medianamente abastado, não se encontra o rudimento, o esboço sequer, dos órgãos funcionais de uma cidade. São esses os grandes resultados da escravidão em trezentos anos (NABUCO, 1982, p.80-81).

O território do engenho, isolado abriga escravos, agregados do estabelecimento, camaradas, capangas, com poucas relações entre o povo ligado aos proprietários e os estranhos. Aqueles estão divididos em lutas por terras num território onde a justiça é precária e não há lugar para a aparição de cidades, vivificando com capitais e recursos o interior (ibid., p.81).

Lembremos que mesmo no auge minerador jamais uma atividade superou em renda e prestígio o Nordeste açucareiro. Na região das Minas, onde se observa uma estratificação social menos rígida e uma concentração de renda também mais favorável ao aparecimento de um desenvolvimento endógeno, este esbarra, ainda segundo Furtado, com a proibição do fabrico de manufaturas na colônia e o precário conhecimento técnico do elemento português. Esta se reafirma como colônia de exploração no sentido mais estrito do termo, subordinando à Coroa qualquer interesse eventualmente surgido na região, como ocorre com a Inconfidência Mineira, aliás não percebida por Simonsen como um movimento de cunho nacionalista inspirado, como foi, pela Independência americana. $\mathrm{Na}$ realidade, o ciclo da mineração dá lugar a uma grande crise no Centro-sul, dado o atraso dos seus habitantes, a falta de aparelhamentos técnicos e a alta proporção da população escrava que impede um progresso baseado no comércio interno, como indica, aliás, o próprio Simonsen.

É significativo que, após o Tratado de Methuen, o ouro brasileiro contribui antes para o progresso inglês do que para o enriquecimento de Portugal. Nosso autor valoriza a importância da colônia para manutenção do reino empobrecido, ao mesmo tempo que ela assume uma singular importância no surgimento do capitalismo industrial:

Lucrou, assim, a Inglaterra bem mais do que Portugal com as descobertas dos bandeirantes paulistas.

Por um desses paradoxos, de que a história é tão rica, os escravos africanos, que o ouro dos mineradores brasileiros introduziu para labutar nos sertões brasileiros, trabalharam poderosamente para o aperfeiçoamento das condições sociais e políticas do povo daquela grande nação, melhorando consideravelmente as condições do trabalho agrícola nas Ilhas Britânicas.

Sob um ponto de vista internacional, é de registrar a opinião de Sombart, que atribui ao aparecimento do ouro brasileiro uma nova etapa no período do capitalismo. Acrescenta este autor:

Sem a descoberta (acidental!) das jazidas de metais preciosos sobre as alturas das Cordilheiras e nos vales do Brasil, não teríamos o homem econômico moderno (SIMONSEN, 1978, p.268).

No Brasil, o ouro ocupou em definitivo o sertão, permitiu a construção das primeiras cidades no interior, criou um grande mercado de gados e tropas, estimulando a ocupação definitiva das regiões sulinas pelos paulistas e tornou o Rio de Janeiro a capital brasileira, criando aí elementos de progresso futuro, bem como concentrou capitais 
que facilitariam, no século XIX, o surgimento do café no Vale do Paraíba (ibid., p. 268). Outra visão teria Paulo Prado em Retrato do Brasil, publicado em 1928, que percebe na colonização a construção fundamental do atraso e da "tristeza" nacionais.

Retomemos neste ponto do texto a contribuição que nos parece duradoura do livro de Roberto Simonsen. Deve-se lembrar com Afrânio Peixoto, no prefácio ao livro de Simonsen, seu pioneirismo. Ele constitui a primeira tentativa bem-sucedida de escrever uma história econômica, em oposição às existentes histórias políticas e administrativas do Brasil. Mais do que isso, a história econômica de Simonsen buscava a "infraestrutura decisiva e fundamental da história descritiva tradicional", permitindo ver a história da civilização como um todo coeso e não mais uma história do Brasil separada da história da América e do mundo.

Simonsen destaca a importância da história econômica para a compreensão da história política e militar nos tempos modernos, acentuando a pequena importância a ela conferida não apenas nas faculdades superiores do Brasil, mas inclusive na Inglaterra e Estados Unidos. Destaca ainda Simonsen o pequeno interesse dos historiadores nacionais pelo tema, ressalvando, entretanto, alguns, como Varnhagen, Capistrano de Abreu e, sobretudo, Pandiá Calógeras.

O livro de Simonsen vem, pois, preencher diversas lacunas, políticas e acadêmicas. O livro destacará, segundo seu autor, a era colonial, por "ter sido na era colonial que se formou a trama social asseguradora da estrutura unitária do País, buscando clarificar os fatores externos que influenciaram o nosso período embrionário, que tiveram e que continuam a atuar na modelagem da nossa formação econômica" (SIMONSEN, 1978, p.25). É nesse sentido que Simonsen estudará inicialmente o período de transição para o capitalismo na Europa, enfatizando a revolução comercial como condição prévia ao nascimento da revolução industrial. Na esteira da revolução comercial formam-se grandes países agrícolas dentro de uma nova divisão do trabalho e são adotadas pelos grandes e emergentes estados nacionais definidas políticas coloniais que atuaram em nosso passado e ainda atuavam, dada a natureza tropical da maior parte da nossa produção.
É, pois, a partir da situação colonial que se examinará a formação e a atualidade econômica do Brasil, destacando as diferentes condições em que se desenvolve a nossa economia vis-à-vis a das demais nações cujas vidas começaram contemporaneamente à nossa. No Brasil, a colonização teve de recorrer à agricultura, em um meio pouco atraente ao elemento europeu e adstrito a produtos tropicais, trazendo os portugueses uma grande massa de população africana que se reuniu à primitiva população autóctone.

A partir daí Simonsen organiza seus temas, sumariando os primórdios da invasão portuguesa, bem como da Espanha, em sua relação com a expansão comercial e o domínio e aproveitamento dos novos territórios, ultramarinos. Passa em seguida à forma inicial de aproveitamento das terras de Santa Cruz num contexto de expansão comercial da Índia e do Oriente e examina as políticas coloniais criadas para o Brasil como ponto de partida para a economia do açúcar. O ciclo do açúcar, na gênese de uma colônia marcada pela grande exploração de produtos tropicais com mão de obra servil, primeiro indígena e logo africana; a expansão da pecuária e sua importância para a unidade do Brasil; o ciclo da mineração, relacionado com a expansão paulista para o interior; os fundamentos da ocupação do Amazonas; o balanço do comércio da era colonial e os primeiros momentos de vida autônoma após a vinda de D. João VI ao Brasil. Todos esses temas são levantados de forma a compor uma agenda detalhada e complexa de problemas para os historiadores futuros da economia brasileira, mas não apenas da economia.

Ressalte-se, em contraposição, que a visão de Simonsen, seguindo, por exemplo, a visão de Brasil e de mundo de Varnhagen, valoriza uma continuidade ideológica entre o regime colonial brasileiro e o Brasil independente e, por outro lado, a exploração da colônia por Portugal e, mais amplamente, pelo nascente capitalismo europeu. Queremos dizer que aquele regime é valorizado em uma construção positiva da civilização moderna europeia e do Brasil visto por Simonsen à época em que escrevia o livro. Neste sentido, pode-se dizer que sua história realça a tradição e os elementos conservadores na construção da ordem e progresso republicana tão cara para o autor. 
É outra a visão de Brasil e de mundo de Caio Prado Júnior ou de Celso Furtado. Para estes, nos seus livros fundamentais sobre a colônia, há uma ruptura entre a colônia e o Brasil independente, bem como entre o Império e a República, há rupturas também entre o fim da ordem escravocrata e o trabalho assalariado, entre um regime econômico baseado na lavoura ainda vigente na República Velha e a expansão da industrialização. Ao mesmo tempo, essas rupturas deixam cicatrizes ao lado de novas perspectivas. Por exemplo, permanecem o paralelismo cromático-social da população, a difícil integração dos afrodescendentes no mercado de trabalho, a problemática construção de uma democracia e de uma soberania nacional consistentes, entre outros exemplos.

Em outros termos, essas rupturas são a ultrapassagem de um núcleo colonial ainda persistente na nossa formação econômica e social, no sentido de uma nação, isto é, de uma formação constituída por laços de solidariedade ditados por uma cultura comum. Este é um conceito bem explícito em Caio Prado, menos aparente, mas não menos presente em Furtado, e que remonta á tradição democrática que Joaquim Nabuco tão exemplarmente ajudou a construir. O conceito de nação representa um ideal ético bastante diverso da civilização utilitarista buscada por Simonsen.

Frente a estes autores, Simonsen tampouco é um liberal da Escola de Manchester, ligandose antes a vertentes teóricas historicistas que valorizam o papel do Estado na construção do nosso capitalismo, o que o coloca próximo de Caio Prado e de Furtado, na sua ênfase na relação entre a formação econômica e a história, ou na valorização do desenvolvimento industrial. Estes são autores fundamentais no período desenvolvimentista brasileiro, entre 1930 e 1964. Contudo, a nosso ver se conserva, enquanto historiador, como membro proeminente da elite paulista e pedagogo da elite, formulando uma visão da história também elitista. A nosso ver, a tradição democrática de Nabuco, Sérgio Buarque, Caio Prado e Furtado coloca estes, ao contrário, digamos um pouco provocativamente, como intelectuais orgânicos da grande massa que se transforma lentamente no povo brasileiro.

\section{Referências}

SIMONSEN, Roberto Cochrane. História Econômica do Brasil: 1500/1820, $8^{\mathrm{a}}$ edição; Editora Nacional, São Paulo, 1978;

PRADO JÚNIOR, Caio. Formação do Brasil Contemporâneo-Colônia, 16 ${ }^{\mathrm{a}}$ edição; Editora Brasiliense, São Paulo, 1979;

FURTADO, Celso. Formação Econômica do Brasil, 12 edição; Editora Nacional, São Paulo, 1974;

NABUCO, Joaquim. Joaquim Nabuco: polítical organizadora Paula Beiguelman; Editora Ática, São Paulo, 1982;

Essencial Joaquim Nabucol organização e introdução de Evaldo Cabral de Mello; Penguin Classics/ Companhia das Letras, São Paulo, 2010.

HOLANDA, Sérgio Buarque de. Raizes do Brasil, $26^{\mathrm{a}}$ edição; Companhia das Letras, São Paulo, 1995;

PRADO, Paulo. Retrato do Brasil: ensaio sobre a tristeza brasileira, $2^{a}$ edição; São Paulo: IBRASA, Brasília: INL, 1981.

Submissão: 16/10/2013

Aprovação: 10/2014 